\title{
Growth of Li Doped Bismuth Oxide Nanorods and its Electrochemical Performance for the Determination of L-Cysteine
}

\author{
Yong Wen ${ }^{a *}$, Li-zhai Peib, Tian Wei \\ ${ }^{a}$ School of Civil Engineering and Architecture, Xinjiang University, Urumchi, Xinjiang 830047, \\ P. R. China \\ ${ }^{b}$ School of Materials Science and Engineering, Anhui University of Technology, Ma'anshan, Anhui \\ 243002, P. R. China
}

Received: September 22, 2016; Revised: December 25, 2016; Accepted: February 18, 2017

\begin{abstract}
Li doped bismuth oxide nanorods have been prepared using sodium bismuthate and $\mathrm{Li}$ acetate. $\mathrm{X}$-ray diffraction (XRD) pattern shows that the nanorods are composed of monoclinic $\mathrm{Bi}_{2} \mathrm{O}_{4}$ and cubic $\mathrm{LiBi}_{12} \mathrm{O}_{18.50}$ phases. Scanning electron microscopy (SEM) observation shows that the nanorods have the length and diameter of 1-5 $\mu \mathrm{m}$ and 50-350 $\mathrm{nm}$, respectively. The formation of the Li doped bismuth oxide nanorods is closely relative to the hydrothermal conditions. The electrochemical performance for the determination of L-cysteine based on a Li doped bismuth oxide nanorods modified glassy carbon electrode (GCE) has been developed. The CV peak current increases obviously and linearly with increasing the scan rate. Under the optimal conditions, Li doped bismuth oxide nanorods modified GCE exhibits good analytical performance with good reproducibility and stability. The linear range of L-cysteine is $0.0001-2 \mathrm{mM}$ and the detection limit is $0.36 \mu \mathrm{M}$ and $0.17 \mu \mathrm{M}$ for cvp1 and cvp2, respectively.
\end{abstract}

Keywords: Li doped bismuth oxide nanorods, scanning electron microscopy, glassy carbon electrode, electrochemical determination, L-cysteine

\section{Introduction}

In recent years, nanoscale bismuth oxide finds more application in a variety of fields due to large surface area which provides a large number of adsorption sites. ${ }^{1,2}$ Nanoscale bismuth oxide has also attracted much attention owing to electrochemical catalysis and electrochemical stability for the analysis of biological molecules. ${ }^{3,4}$ Glassy carbon electrode (GCE) modified with nanoscale Bi-containing materials, such as zinc bismuthate nanorods, ${ }^{5}$ aluminium bismuthate nanorods, ${ }^{6} \mathrm{Bi}_{2} \mathrm{O}_{3}$ nanorods ${ }^{7}$ and $\mathrm{Bi}_{2} \mathrm{O}_{3}$ microscale and nanoscale particles ${ }^{8}$ has shown good catalytic activity for the electrochemical reduction or oxidation of various biological molecules. The performance of the materials can be improved by doping metal ions. ${ }^{9}$ It has also been observed that the electrochemical performance of the electrodes may be improved by doping metal ions, such as $\mathrm{Li}$ ions. ${ }^{10,11}$ Therefore, it is important to explore the synthesis of the Li doped bismuth oxide nanorods for improving the electrochemical performance to detect biological molecules. However, to date, the synthesis of Li doped bismuth oxide nanorods has not been reported.

L-cysteine (L-CySH) belongs to important amino acids which has an essential role in biological system. ${ }^{12}$ Abnormal level of L-cysteine can cause a number of disease, such as liver damage, fat and muscle loss, weakness and hair

\footnotetext{
* e-mail: yongwen1982@163.com
}

depigmentation. ${ }^{13}$ Therefore, it is important to develop sensitive method for the determination of L-cysteine. Various methods have been used for the determination of L-cysteine, such as photoelectrochemical detection,,$^{14}$ spectrometric method, ${ }^{15,16}$ chromatographic separation method ${ }^{17}$ and electrochemical method. ${ }^{18}$ Among these methods, electrochemical method using GCE modified with nanoscale materials has been widely reported to improve the selectivity and sensitivity for the detection of organic acids. However, the electrochemical determination of L-cysteine on the conventional electrodes requires large overpotential which significantly reduces the selectivity. ${ }^{19,20}$ Large overpotential also causes the formation of oxide at the surface of the GCEs as well as the fouling effect. Therefore, it is essential to explore suitable modified materials for the determination of L-cysteine.

Hydrothermal route is an effective method for the synthesis of nanoscale materials. ${ }^{21-24}$ In this work, a one-step hydrothermal approach for the synthesis of Li doped bismuth oxide nanorods has been developed. The formation process of Li doped bismuth oxide nanorods has been analyzed by controlling the hydrothermal parameters, such as hydrothermal temperature and reaction time. The mechanical attachment method was used to modify the surface of the GCE by attaching the Li doped bismuth oxide nanorods. And the electrochemical performance of the Li doped bismuth oxide nanorods modified GCE for the determination of L-cysteine in $\mathrm{KCl}$ solution has been investigated. The Li doped bismuth 
oxide nanorods modified GCE shows good performance for the determination of L-cysteine with high sensitivity, wide detection range and good stability. In addition, the results show that the nanorods modified GCE can act as a promising electrochemical platform for the electrochemical determination of L-cysteine.

\section{Experimental}

Sodium bismuthate (AR grade) was purchased from Aladdin Reagent Co., Ltd. of P. R. China. Lithium acetate (AR grade) and L-cysteine (AR grade) were purchased from Sinopharm Chemical Reagent Co., Ltd. of P. R. China. All other reagents were $\mathrm{AR}$ grade. The $0.1 \mathrm{M} \mathrm{KCl}$ solution was prepared from potassium chloride and deionized water. $\mathrm{Li}$ doped bismuth oxide nanorods were synthesized by the hydrothermal process which was similar to that reported by Lin et al. ${ }^{25}$ Briefly, sodium bismuthate and lithium acetate with the mass ratio of $21: 5$ were mixed with $60 \mathrm{~mL}$ deionized water at room temperature with magnetic stiring for $0.5 \mathrm{~h}$. Then the mixtures with lithium acetate and sodium bismuthate were transferred into a Teflon-lined stainless autoclave. The stainless autoclave was sealed and heated to $80-180^{\circ} \mathrm{C}$ and maintained for $0.5 \mathrm{~h}$ to $24 \mathrm{~h}$. The white precipitates were gained by the centrifugation, washed using deionized water for several times. The Li doped bismuth oxide nanorods products were dried at $60{ }^{\circ} \mathrm{C}$.

The obtained samples were investigated by $\mathrm{X}$-ray diffraction (XRD) (Bruker AXS D8) with a $\mathrm{Cu} \mathrm{K}_{\alpha}$ radiation $(\lambda=1.5406$ $\AA$ ) and scan rate of $0.05^{\circ} \mathrm{s}^{-1}$ in the range of $10^{\circ}$ to $80^{\circ}$ so as to identify the phase of the products. The morphology of the products was analyzed in a nova nanoSEM FEI 430 (FEI, Tokyo, Japan) scanning electron microscopy (SEM).

The Li doped bismuth oxide nanorods modified GCE was prepared by a simple mechanical attachment process. Bare GCE ( $3 \mathrm{~mm}$ in diameter) was polished using 0.05 $\mu \mathrm{m}$ alumina slurry, rinsed throughly with deionized water for several times and dried at room temperature forming a mirror-like surface. $10 \mathrm{mg} \mathrm{Li} \mathrm{doped} \mathrm{bismuth} \mathrm{oxide} \mathrm{nanorods}$ were dispersed into $10 \mathrm{~mL} \mathrm{~N}$, N-dimethylformamide (DMF) solution with magnetic stiring for $1 \mathrm{~h}$. $10 \mu \mathrm{L} \mathrm{Li} \mathrm{doped} \mathrm{bismuth}$ oxide nanorods homogeneous solution was drop-coated on the surface of the GCE using a pipette and dried using an infrared lamp.

For cyclic voltammogram (CV) measurement, electrochemical measurements were performed on a CHI604D electrochemical workstation (Shanghai Chenhua Instrument Co., P. R. China) using a conventional three electrode system: a Li doped bismuth oxide nanorods modified GCE, a platinum counter electrode and a saturated calomel reference electrode. The $\mathrm{CVs}$ of L-cysteine with different concentrations at the $\mathrm{Li}$ doped bismuth oxide nanorods modified GCE were measured in $0.1 \mathrm{M} \mathrm{KCl}$ solution using different scan rates.

\section{Results and Discussion}

The crystal structure of the products obtained from the hydrothermal conditions of $180^{\circ} \mathrm{C}$ for $24 \mathrm{~h}$ was characterized by XRD analysis. As shown in Figure 1, most of the XRD diffraction peaks in the spectrum can be indexed to monoclinic $\mathrm{Bi}_{2} \mathrm{O}_{4}$ phase (JCPDS card No. 50-0864). The main monoclinic $\mathrm{Bi}_{2} \mathrm{O}_{4}$ phase is very different from the tetragonal $\mathrm{Bi}_{2} \mathrm{O}_{3}$ phase of the bismuth oxide nanoscale materials synthesized from other methods. ${ }^{1,2,21,24}$ Besides monoclinic $\mathrm{Bi}_{2} \mathrm{O}_{4}$ phase, cubic $\mathrm{LiBi}_{12} \mathrm{O}_{18.50}$ phase (JCPDS card No. 50-0082) is also indexed. No other phases are observed besides monoclinic $\mathrm{Bi}_{2} \mathrm{O}_{4}$ and cubic $\mathrm{LiBi}_{12} \mathrm{O}_{18.50}$ phases. $\mathrm{Li}$ ions exist in the products as the cubic $\mathrm{LiBi}_{12} \mathrm{O}_{18.50}$ phase showing that the products are composed of Li doped bismuth oxide.

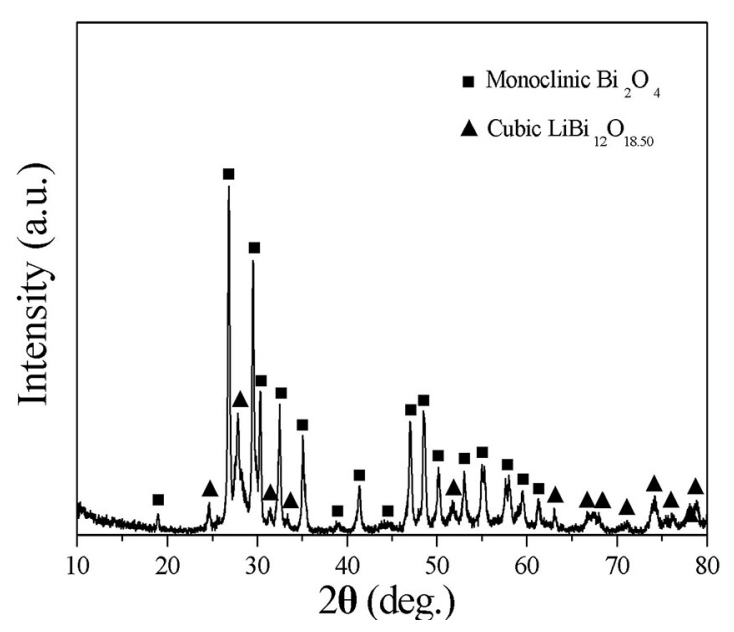

Figure 1. XRD pattern of the products synthesized from the hydrothermal conditions of $180^{\circ} \mathrm{C}$ for $24 \mathrm{~h}$.

The morphology of the products synthesized from the hydrothermal conditions of $180^{\circ} \mathrm{C}$ for $24 \mathrm{~h}$ was observed by SEM, as shown in Figure 2. From the SEM image with low magnification (Figure 2a), it is clearly seen that the products are composed of a large amount of nanoscale rod-shaped morphology. The nanorods have typical length of 1-5 $\mu \mathrm{m}$. Figure $2 b$ shows the SEM image with higher magnification. The nanorods consist of semi-circular tips. The diameter of the nanorods is about $50-350 \mathrm{~nm}$. Combining the XRD pattern with SEM observation, it is confirmed that the products are composed of Li doped bismuth oxide nanorods.

For the synthesis of the Li doped bismuth oxide nanorods, no templates and surfactants were used. Only sodium bismuthate and Li acetate were adopted as the raw materials. Detailed morphology evolution of the products using different reaction times and hydrothermal temperatures were examined by SEM at different growth stages. The SEM images of the products obtained from the hydrothermal conditions of $180{ }^{\circ} \mathrm{C}$ for different reaction times $(0.5 \mathrm{~h}, 6 \mathrm{~h}$ and $12 \mathrm{~h})$ are shown in 


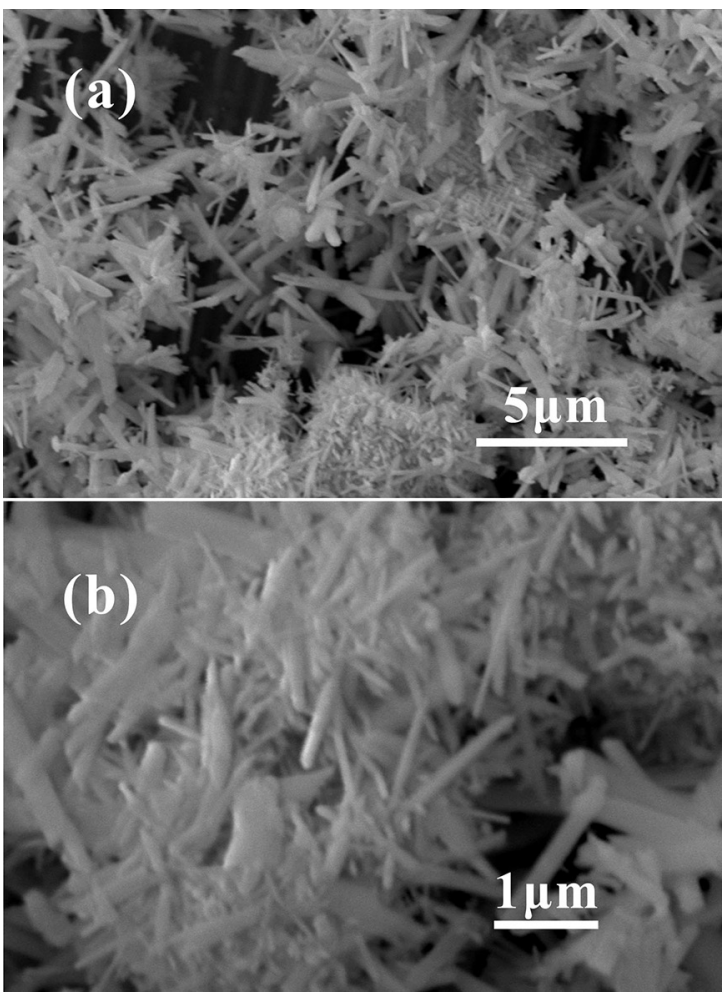

Figure 2. SEM image of the products with different magnifications synthesized from the hydrothermal conditions of $180^{\circ} \mathrm{C}$ for $24 \mathrm{~h}$.

Figure 3. At the initial stage of the hydrothermal reaction $(0.5$ h), the products tend to aggregate together to form irregular particles and nanosphere-shaped structures (Figure 3a and $3 b)$. The size of the irregular particles and nanosphereshaped structures is about $50-500 \mathrm{~nm}$. As the reaction time proceeds to $6 \mathrm{~h}$, some nanorods are found to be formed in the products besides irrgular particles, as shown in Figure $3 \mathrm{c}$ and $3 \mathrm{~d}$. The diameter and length of the nanorods are about 40-200 $\mathrm{nm}$ and $1 \mu \mathrm{m}$, respectively. When the hydrothermal reaction time increases to $12 \mathrm{~h}$, the amount of the nanorods increases obviously and irregular particles decrease (Figure $3 \mathrm{e}$ and $3 \mathrm{f}$ ). The diameter and length of the nanorods increase to 50-300 $\mathrm{nm}$ and $2 \mu \mathrm{m}$, respectively. The reaction timedependent results suggest that the nanorods originate from the irregular and nanosphere-shaped structures which is similar to those reported by other groups. ${ }^{5-7,21}$ With the increase of the reaction time, the diameter and length of the nanorods increase continuously. Figure 4 shows the SEM images of the products obtained from the hydrothermal conditions of $80^{\circ} \mathrm{C}$ and $120^{\circ} \mathrm{C}$, respectively for $24 \mathrm{~h}$. The products are totally composed of elliptic particles with the size of 150 $\mathrm{nm}$ when the hydrothermal temperature is $80^{\circ} \mathrm{C}$ (Figure $4 \mathrm{a}$ and $4 \mathrm{~b}$ ). As increasing the hydrothermal temperature to 120 ${ }^{\circ} \mathrm{C}$, the products mainly consist of irregular particles (Figure $4 \mathrm{c}$ and $4 \mathrm{~d}$ ). Some nanorods with the diameter and length of 40-300 nm and $500 \mathrm{~nm}-1 \mu \mathrm{m}$, respectively are observed besides irregular particles. These nanorods obtained from high temperature $\left(120^{\circ} \mathrm{C}\right)$ are considered to be formed from the nanoscale elliptic particles at low temperature $\left(80^{\circ} \mathrm{C}\right)$. The results further confirm that the nanorods originate from the nucleau of the nanoscale particles. According to the above results, $180^{\circ} \mathrm{C}$ for $24 \mathrm{~h}$ is the optical hydrothermal reaction conditions for the formation of the $\mathrm{Li}$ doped bismuth oxide nanorods.

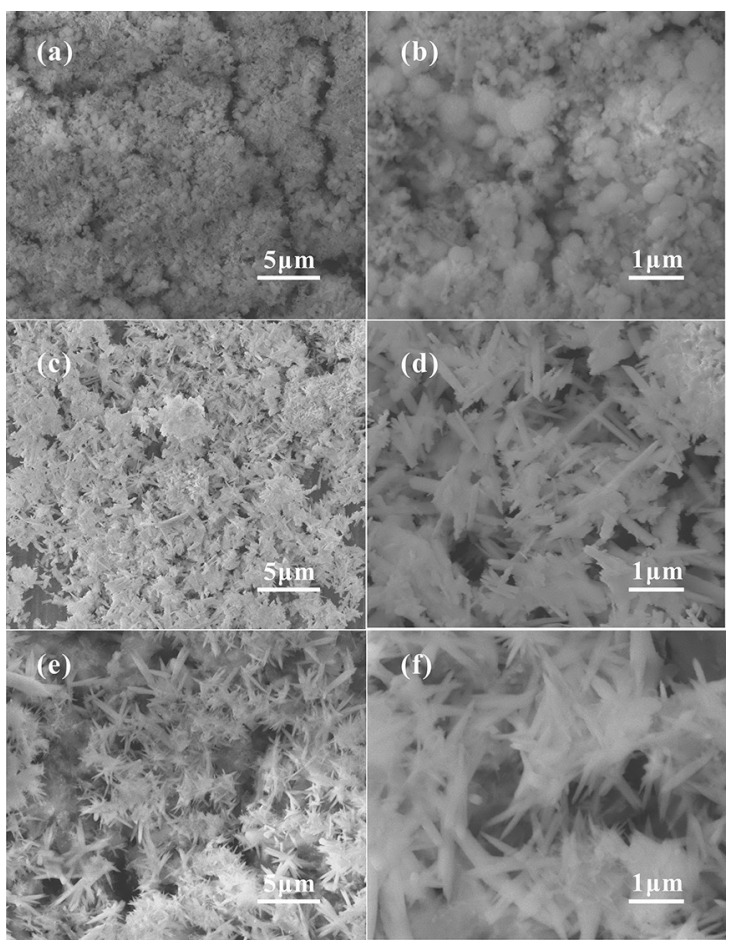

Figure 3. SEM image of the products synthesized from the hydrothermal conditions of $180^{\circ} \mathrm{C}$ for different times. (a) and (b) $0.5 \mathrm{~h},(\mathrm{c})$ and (d) $6 \mathrm{~h}$, (e) and (f) $12 \mathrm{~h}$.

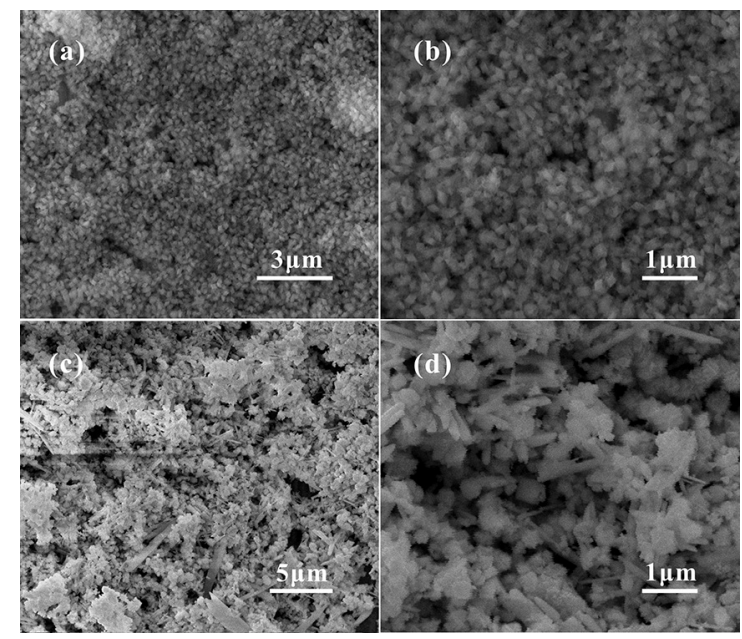

Figure 4. SEM image of the products synthesized from the hydrothermal conditions of different hydrothermal temperatures for $24 \mathrm{~h}$. (a) and (b) $80^{\circ} \mathrm{C}$, (c) and (d) $120^{\circ} \mathrm{C}$. 
Based on the morphology evolution of the products from different hydrothermal conditions, the possible formation process of the Li doped bismuth oxide nanorods is shown in Figure 5. The morphology evolution of the products is relative to the reaction time and hydrothermal temperature. At the initial reaction stage, sodium bismuthate is decomposed to form bismuth oxide with monoclinic $\mathrm{Bi}_{2} \mathrm{O}_{4}$. And some sodium bismuthate reacts with $\mathrm{Li}$ acetate forming $\mathrm{Li}$ bismuthate with cubic $\mathrm{LiBi}_{12} \mathrm{O}_{18.50}$ phase. The bismuth oxide with monoclinic $\mathrm{Bi}_{2} \mathrm{O}_{4}$ phase and $\mathrm{Li}$ bismuthate with cubic $\mathrm{LiBi}_{12} \mathrm{O}_{18.50}$ phase precipitate from the hydrothermal solution when they reach supersaturated state. Then the bismuth oxide and Li bismuthate aggregate forming nanoscale nucleau with monoclinic $\mathrm{Bi}_{2} \mathrm{O}_{4}$ and cubic $\mathrm{LiBi}_{12} \mathrm{O}_{18.50}$ phases. The Li doped bismuth oxide nanorods originate from these nanoscale nucleau according to "Ostwald rippening process " under the hydrothermal growth conditions. ${ }^{26-30}$ The diameter and length of the Li doped bismuth oxide nanorods increase obviously with the increase of the reaction time and hydrothermal temperature leading to the final formation of the Li doped bismuth oxide nanorods.
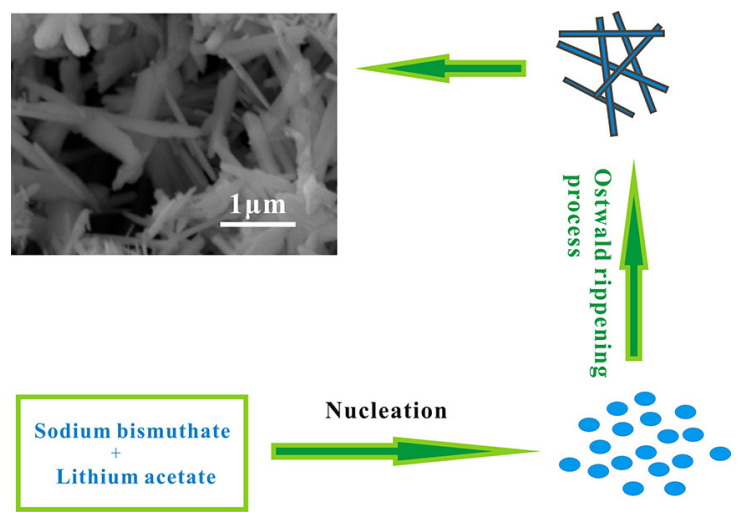

Figure 5. The growth process schematic of the Li doped bismuth oxide nanorods.

$\mathrm{KCl}$ buffer is common buffer solution for the electrochemical analysis of organic molecules. Therefore, $0.1 \mathrm{M} \mathrm{KCl}$ buffer solution is selected for the electrochemical analysis of L-cysteine. The electrochemical behaviors of L-cysteine at the Li doped bismuth oxide nanorods modified GCE have been investigated by cyclic voltammetry with $0.1 \mathrm{M} \mathrm{KCl}$ as the electrolyte and scan rate of $50 \mathrm{mV} \cdot \mathrm{s}^{-1}$. Figure 6 indicates the CV curves at bare GCE and Li doped bismuth oxide nanorods modified GCE with and without L-cysteine from $-1.0 \mathrm{~V}$ to $+1.0 \mathrm{~V}$. No electrochemical signals exist in the CVs at the bare GCE in the mixed solution of $2 \mathrm{mM}$ L-cysteine and $0.1 \mathrm{M} \mathrm{KCl}$, and Li doped bismuth oxide nanorods GCE in $0.1 \mathrm{M} \mathrm{KCl}$ solution. The results show that the bare electrode has no electrochemical activity toward L-cysteine in $\mathrm{KCl}$ solution. And Li doped bismuth oxide nanorods modified $\mathrm{GCE}$ has also no electrochemical activity toward $\mathrm{KCl}$. It is noticed that two pairs of electrochemical CV peaks exist in the $\mathrm{CV}$ curve at the $\mathrm{Li}$ doped bismuth oxide nanorods modified GCE in the mixed solution of $2 \mathrm{mM}$ L-cysteine and $0.1 \mathrm{M} \mathrm{KCl}$. It is evident that the Li doped bismuth oxide nanorods modified GCE exhibits a significant electrocatalytic activity toward L-cysteine. Different from the reports by other groups, an irreversible or a pair of electrochemical CV peaks were generally observed using other modified GCEs. For example, Luo et al. ${ }^{12}$ reported that a pair of electrochemical $\mathrm{CV}$ peaks at about $+0.24 \mathrm{~V}$ and $+0.36 \mathrm{~V}$, respectively using graphene oxide/carboxylated multiwalled carbon nanotube/ manganese dioxide/gold nanoparticles composite (GO/CCNTs/ AuNPs@ $\mathrm{MnO}_{2}$ ) modified GCE in L-cysteine solution. An irreversible electrochemical $\mathrm{CV}$ peak located at about +1.05 $\mathrm{V}$ was observed at the $\mathrm{Fe}_{2} \mathrm{O}_{3}$ nanoparticles supported on $\mathrm{N}$-doped graphene $\left(\mathrm{Fe}_{2} \mathrm{O}_{3} \mathrm{NPs} / \mathrm{N}-\mathrm{GR}\right) \mathrm{GCE}$ in the presence of $0.5 \mathrm{mM}$ L-cysteine and $0.1 \mathrm{PBS}$ with the scan rate of 50 $\mathrm{mV} \cdot \mathrm{s}^{-1} \cdot{ }^{18}$ A pair of semi-reversible redox peaks at $-0.07 \mathrm{~V}$ and $-0.52 \mathrm{~V}$ was observed at the $\mathrm{Zn}$ bismuthate nanorods modified GCE in $2 \mathrm{mM}$ L-cysteine and $0.1 \mathrm{M} \mathrm{KCl}$ solution. ${ }^{5}$ Two pairs of CV peaks of L-cysteine at the polyaniline/ $\mathrm{CuGeO}_{3}$ nanowires modified GCE were located at $+0.24 \mathrm{~V}$ (cvp1), +0.07 V (cvp2) and +0.05 V (cvp1'), -0.47 V (cvp2') in $2 \mathrm{mM}$ L-cysteine. ${ }^{31}$ Two pairs of electrochemical CV peaks exist at $-0.41 \mathrm{~V},+0.25 \mathrm{~V}\left(\mathrm{cvp} 1\right.$ and $\left.\mathrm{cvp} 1^{\prime}\right)$ and -0.93 $\mathrm{V},-0.44 \mathrm{~V}(\mathrm{cvp} 2$ and cvp2'), respectively at the Li doped bismuth oxide nanorods modified GCE in $2 \mathrm{mM}$ L-cysteine. Electrochemical signals are only observed from the $\mathrm{CV}$ curve at the Li doped bismuth oxide nanorods modified GCE in the mixed solution of $2 \mathrm{mM} \mathrm{L}$-cysteine and $0.1 \mathrm{M} \mathrm{KCl}$ indicating that the electrochemical $\mathrm{CV}$ peaks originate from L-cysteine and Li doped bismuth oxide nanorods.

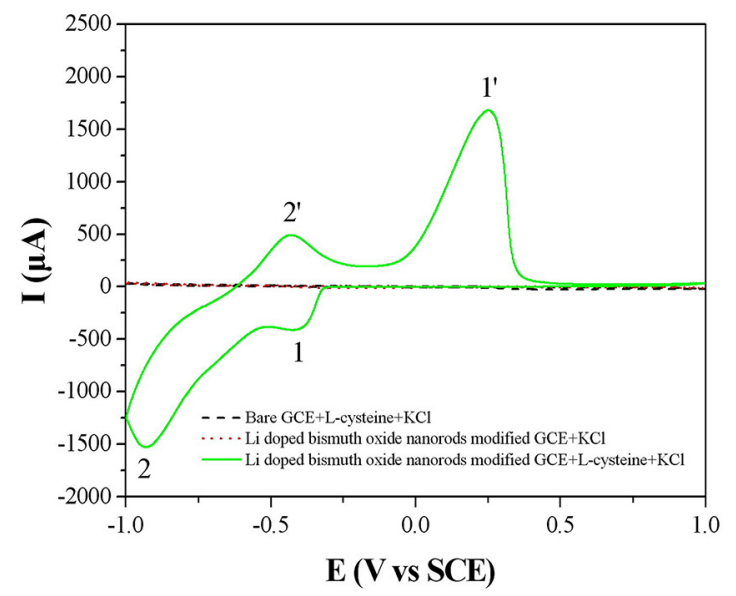

Figure 6. $\mathrm{CV}$ of $2 \mathrm{mM}$ L-cysteine at bare $\mathrm{GCE}$ in $0.1 \mathrm{M} \mathrm{KCl}$ solution, $\mathrm{CV}$ at the $\mathrm{Li}$ doped bismuth oxide nanorods modified GCE in $0.1 \mathrm{M} \mathrm{KCl}$ solution and CV of $2 \mathrm{mM} \mathrm{L}$-cysteine at the Li doped bismuth oxide nanorods modified GCE in $0.1 \mathrm{M} \mathrm{KCl}$ solution. Scan rate, $50 \mathrm{mVs}^{-1}$. 
The intensities of the electrochemical anodic peaks and cathodic peaks are different showing that the electrochemical $\mathrm{CV}$ peaks contribute to two pairs of semi-reversible peaks. Figure 7 indicates the CVs of $2 \mathrm{mM}$ L-cysteine at the $\mathrm{Li}$ doped bismuth oxide nanorods modified GCE using different initial scan potentials $(+0.3 \mathrm{~V},+0.2 \mathrm{~V},-0.6 \mathrm{~V}$ and $-1.0 \mathrm{~V})$. The scan rate is $50 \mathrm{mVs}^{-1}$. No CV peaks exist in the CVs of L-cysteine when the initial scan potential is $+0.3 \mathrm{~V}$ and +0.2 $\mathrm{V}$, respectively which is larger than that of cvp1. When the initial scan potential decreases to $-0.6 \mathrm{~V}$ which is smaller than that of cvp1, a pair of electrochemical CV peaks are observed. With the initial scan potential decreasing to $-1.0 \mathrm{~V}$, two pairs of electrochemical CV peaks are seen. Therefore, the potential cvp1 and cvp2 originates from the potential cvp1' and cvp2'. The results show that two pairs of CV peaks belong to semi-reversible CV peaks.

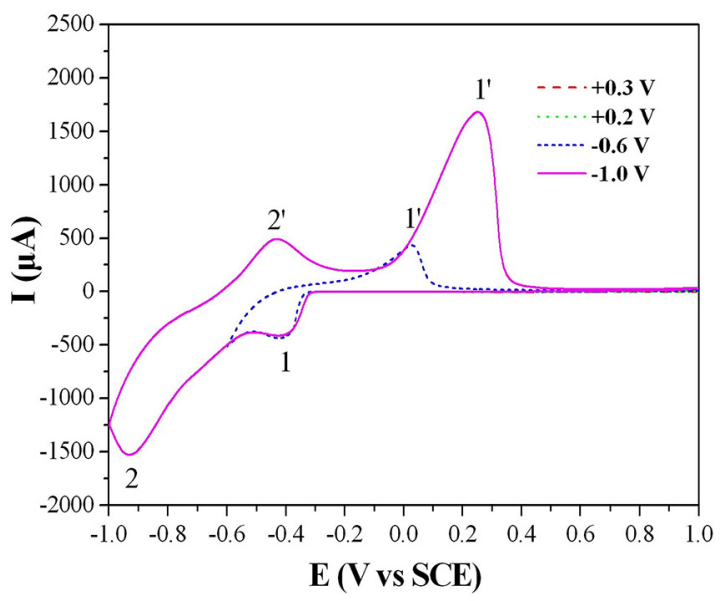

Figure 7. CVs of $2 \mathrm{mM}$ L-cysteine at the Li doped bismuth oxide nanorods modified GCE using different initial potentials. Scan rate, $50 \mathrm{mVs}^{-1}$.

It had been reported that the anodic peak existed at the potential higher than $-0.4 \mathrm{~V}$ at the vitamin $\mathrm{B}_{12}$ modified pyrolytic graphite electrode was associated to the oxidation process of L-cysteine to L-cystine (CySSCy) and the reduction of L-cystine. ${ }^{32} \mathrm{~A}$ pair of redox electrochemical $\mathrm{CV}$ peaks at the manganese dioxide-carbon nanoscale composite modified GCE were also reported to be caused from the oxidation and reduction between L-cysteine and CySSCy. ${ }^{33} \mathrm{~A}$ pair of electrochemical $\mathrm{CV}$ peaks located at $-0.07 \mathrm{~V}$ and $-0.52 \mathrm{~V}$ were ascribed to the oxidation and reduction process between L-cysteine and CySSCy. ${ }^{5}$ Similar to the above reports, $\mathrm{Li}$ doped bismuth oxide nanorods modified GCE may also participate the electrochemical oxidiation and reduction process between L-cysteine and L-cystine (CySSCy). The oxidation and reduction process of L-cysteine for cvp1 and cvp1' are shown as follows:

$$
\mathrm{CySH} \rightarrow \mathrm{CyS}^{-}+\mathrm{H}^{+}
$$

$$
\begin{aligned}
& \mathrm{CyS}^{-}-\mathrm{e} \rightarrow \mathrm{CyS}^{*}(2) \\
& 2 \mathrm{Cys}^{*} \rightarrow \text { CySSCy }(3) \\
& \text { CySSCy }+ \text { Nannorods } \rightarrow \mathrm{CyS}- \\
& \text { nanorods }-\mathrm{CyS}(4) \\
& \mathrm{CyS}-\text { nanorods }-\mathrm{CyS}+2 \mathrm{e} \rightarrow 2 \mathrm{CyS}^{-}
\end{aligned}
$$

It was reported that the electrochemical $\mathrm{CV}$ peaks located at $-0.45 \mathrm{~V}$ and $-0.65 \mathrm{~V}$ were contributed to the adsorption and desorption behavior of L-cysteine and L-cystine at the surface of gold electrode. ${ }^{34}$ The electrochemical $\mathrm{CV}$ peaks located at $-0.04 \mathrm{~V}$ and $-0.35 \mathrm{~V}$ for cvp2 and cvp2', respectively at the copper germanate nanowires modified GCE were also contributed to the adsorption and desorption process of L-cysteine and L-cystine. ${ }^{35}$ Similar to the electrochemical $\mathrm{CV}$ peaks for the above reports, the electrochemical $\mathrm{CV}$ peaks at $-0.93 \mathrm{~V},-0.44 \mathrm{~V}$ for cvp2 and cvp2', respectively at the Li doped bismuth oxide nanorods modified GCE is considered to be contributed to the adsorption and desorption process of L-cysteine and L-cystine.

It was reported that the electrochemical behaviors of L-cysteine at the modified GCEs are closely relative to the scan rate. ${ }^{28,33,35}$ Figure 8 shows the electrochemical CV curves of $2 \mathrm{mM}$ L-cysteine in $0.1 \mathrm{M} \mathrm{KCl}$ solution at the Li doped bismuth oxide nanorods modified GCE using the scan rate from $25 \mathrm{mV} \cdot \mathrm{s}^{-1}$ to $200 \mathrm{mV} \cdot \mathrm{s}^{-1}$. As shown in the inset of upper-left part of Figure 8, the intensities of the electrochemical $\mathrm{CV}$ peaks are linear to the scan rate ranging from $25 \mathrm{mV} \cdot \mathrm{s}^{-1}$ to $200 \mathrm{mV} \cdot \mathrm{s}^{-1}$ which is similar to that reported by other groups. ${ }^{36-39}$ The correlation coefficient $(\mathrm{R})$ for cvp 1 and cvp2 is 0.996 and 0.992 , respectively. The role of the scan rate on the electrochemical behaviors shows that the electrochemical process of L-cysteine at the Li-doped bismuth oxide nanorods modified GCE can be controlled by a surface confined process. ${ }^{40,41}$

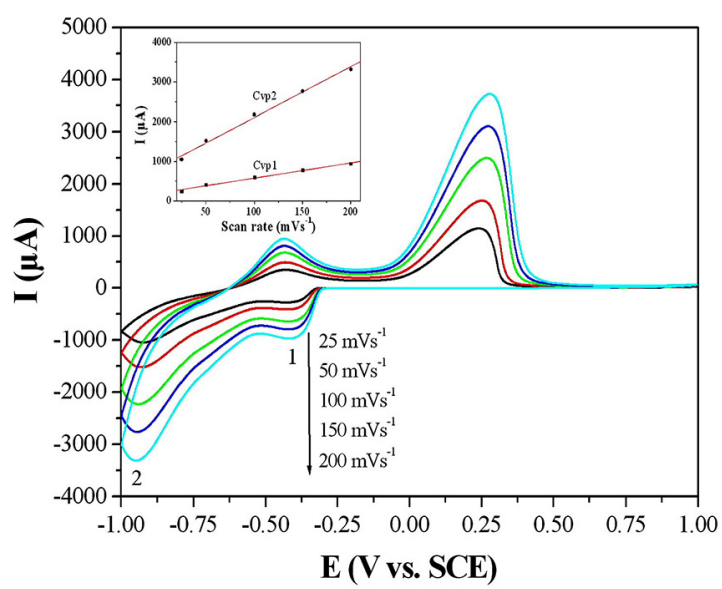

Figure 8. CVs of $2 \mathrm{mM} \mathrm{L}$-cysteine in $0.1 \mathrm{M} \mathrm{KCl}$ solution at the $\mathrm{Li}$ doped bismuth oxide nanorods modified GCE using different scan rates. The inset in the upper-left part is the relationship of the peak current and scan rate. 
The effect of $\mathrm{pH}$ values on the electrochemical responses of L-cysteine on the Li doped bismuth oxide nanorods modified GCE was investigated in the $\mathrm{pH}$ range of 5.0-9.0 by the cyclic voltammograms. As shown in Figure 9, the current of the $\mathrm{CV}$ peaks of L-cysteine increases up to $\mathrm{pH}$ 7.0 and then starts to decrease at higher $\mathrm{pH}$ value, which is similar to that reported by other groups. ${ }^{36,42}$ The result shows that the Li doped bismuth oxide nanorods modified GCE exhibits good electrocatalytic performance toward L-cysteine at $\mathrm{pH}$ 7.0.

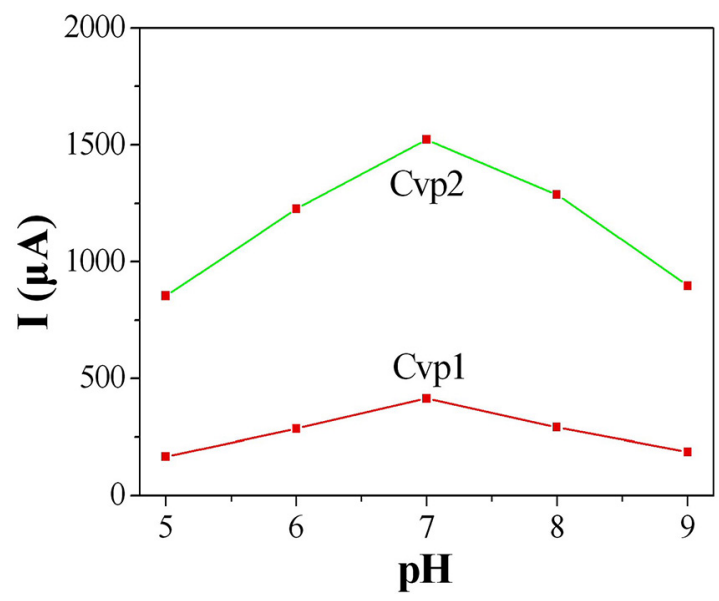

Figure 9. Effect of $\mathrm{pH}$ on the electrochemical singal of $2 \mathrm{mM}$ L-cysteine in $0.1 \mathrm{M} \mathrm{KCl}$ solution at the Li doped bismuth oxide nanorods modified GCE. Scan rate, $50 \mathrm{mVs}^{-1}$.

The detection limit of L-cysteine was determined using Li-doped bismuth oxide nanorods modified GCE by controlling the L-cysteine concentration in $0.1 \mathrm{KCl}$ solution with the scan rate of $50 \mathrm{mV} \cdot \mathrm{s}^{-1}$. Figure 10 shows the $\mathrm{CVs}$ of L-cysteine with different concentrations at the Li doped bismuth oxide nanorods modified GCE. Voltammograms show that the peak current increases obviously and linearly with the L-cysteine concentration increasing from $0.0001 \mathrm{mM}$ to $2 \mathrm{mM}$ (the inset of the upper-left part of Figure 10). Table 1 shows the analytical parameters for the determination of L-cysteine using Li doped bismuth oxide nanorods modified GCE. The correlation coefficient is 0.974 and 0.985 for cvp 1 and cvp2, respectively which is a little lower than that using other electrodes reported by other groups..$^{42-46}$ The linear range is $0.0001-2 \mathrm{mM}$. According to the signal-to-noise ratio of 3 , the detection limit is estimated to be $0.36 \mu \mathrm{M}$ and $0.17 \mu \mathrm{M}$ for cvp 1 and cvp2, respectively. Table 2 compares the analytical parameters for L-cysteine using different

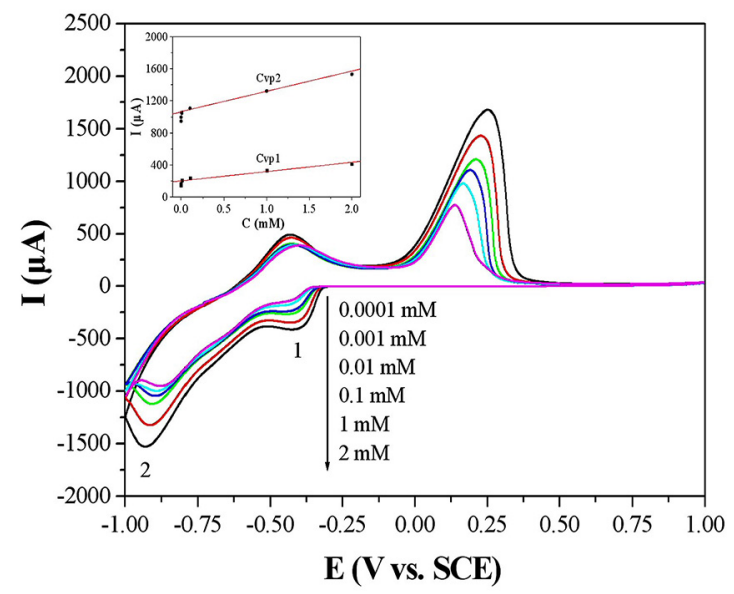

Figure 10. CVs of L-cysteine with different concentrations at the $\mathrm{Li}$ doped bismuth oxide nanorods modified GCE. Scan rate, $50 \mathrm{mVs}^{-1}$. The inset in the upper-left part is the relationship of the peak current and L-cysteine concentration.

electrodes. Comparing the analytical results using other electrodes, the Li doped bismuth oxide nanorods modified GCE possesses a wide linear range and comparable detection limit for L-cysteine.

Some interfering species, such as catechol, hydroquinone, resorcinol and citric acid were measured in $2 \mathrm{mM}$ containing the L-cysteine concentration of $2 \mathrm{mM}$. The potentials of the electrochemical $\mathrm{CV}$ peaks maintain similar showing that no electrochemical signals originate from catechol, hydroquinone, resorcinol and citric acid. As a result, these organic acids have no interfering effect on the oxidation of L-cysteine at the Li doped bismuth oxide nanorods modified GCE.

As a practical use, the preliminary experiments with serum samples have been performed using Li doped bismuth oxide nanorods modified GCE for the determination of L-cysteine. The L-cysteine concentration in the serum samples is 5, 20 and $40 \mu \mathrm{M}$, respectively. The values were calculated from five separate measurements. The recovery of L-cysteine was determined by the standard addition. Table 3 shows the detection results. The result suggests that the Li doped bismuth oxide nanorods mofified GCE is reliable for the detection of L-cysteine.

Stability and reproducibility belong to two important parameters for the electrochemical determination of L-cysteine that should be investigated. The same Li doped bismuth oxide nanorods modified GCE was used in twenty successive measurements of $2 \mathrm{mM} \mathrm{L}$-cysteine in $0.1 \mathrm{M} \mathrm{KCl}$ solution with the scan rate and potential range of $50 \mathrm{mV} \cdot \mathrm{s}^{-1}$

Table 1. Analytical data of L-cysteine using Li doped bismuth oxide nanorods modified GCE.

\begin{tabular}{ccccc}
\hline CV peaks & Regression equation $^{\mathrm{a}}$ & Correlation coefficient $(\mathrm{R})$ & Linear range $(\mathrm{mM})$ & ${\text { Detection limit }(\mu \mathrm{M})^{\mathrm{b}}}^{\mathrm{b}}$ \\
\hline cvp1 & $I_{p}=226.705+93.947 C$ & 0.974 & $0.0001-2$ & 0.36 \\
cvp2 & $I_{p}=1079.084+230.158 C$ & 0.985 & $0.0001-2$ & 0.17 \\
\hline
\end{tabular}

${ }^{\mathrm{a}}$ Where $I_{p}$ and $\mathrm{C}$ refer to the current $(\mu \mathrm{A})$ and L-cysteine concentration $(\mathrm{mM})$, respectively

${ }^{\mathrm{b}}$ The detection limit was calculated according to a signal-to-noise ratio of 3 
Table 2. Comparison for the electrochemical determination of L-cysteine with other electrodes.

\begin{tabular}{|c|c|c|c|}
\hline Electrodes & Linear range $(\mathrm{mM})$ & Detection limit $(\mu \mathrm{M})$ & Ref. \\
\hline Zinc bismuthate nanorods & $0.0001-2$ & 0.074 & [5] \\
\hline Aluminium bismuthate nanorods & $0.001-2$ & 0.56 & {$[6]$} \\
\hline GO/CNTs/AuNPs@ $\mathrm{MnO}_{2}$ & $0.01-7.00$ & 0.0034 & {$[12]$} \\
\hline Copper germanate nanowires modified GCE & $0.001-2$ & 0.9 & {$[35]$} \\
\hline $\mathrm{Pt} / \mathrm{VACNTs}$ modified GCE & $0.001-0.5$ & 0.5 & {$[37]$} \\
\hline $\mathrm{Sb}$ doped $\mathrm{ZnO}$ modified GCE & $0.000075-0.1$ & 0.025 & {$[38]$} \\
\hline $\begin{array}{l}\text { Carbon nanofibers modified carbon paste electrode } \\
\text { (CPE) }\end{array}$ & $0.00015-0.0638$ & 0.1 & [39] \\
\hline Boron-doped CNTs-modified GCE & $0.00078-0.2$ & 0.26 & [43] \\
\hline Boron-doped diamond & $0.001-0.2$ & 0.9 & {$[44]$} \\
\hline Ppy film modified Pt & Up to 0.5 & 1 & {$[45]$} \\
\hline Fluorosurfactant-modified Au & Up to 0.2 & 0.5 & {$[46]$} \\
\hline BB-modified Nafion-coated GCE & $0.01-0.1$ & 0.5 & {$[47]$} \\
\hline MCNTs modified GCE & $0.01-0.5$ & 5.4 & [48] \\
\hline CNTs modified Pt & $0.0005-0.1$ & 0.3 & [49] \\
\hline Multiwall carbon nanotubes & $0.0004-0.115$ & 0.25 & {$[50]$} \\
\hline$p$-Aminophenol modified carbon nanotubes & $0.0005-0.1$ & 0.3 & {$[51]$} \\
\hline Li doped bismuth oxide nanorods & $0.0001-2$ & 0.17 & Present work \\
\hline
\end{tabular}

Table 3. Electrochemical detection of L-cysteine using Li doped bismuth oxide nanorods modified GCE in serum samples.

\begin{tabular}{cccc}
\hline Sample (serum) & Amount added $(\mu \mathrm{M})$ & Amount found $(\mu \mathrm{M})$ (average of five times) & Recovery $(\%)$ \\
\hline 1 & 5 & $4.91 \pm 0.12$ & 97.8 \\
2 & 20 & $19.58 \pm 0.18$ & 98.6 \\
3 & 40 & $40.94 \pm 0.28$ & 102.6 \\
\hline
\end{tabular}

and $-1.0 \mathrm{~V}$ to $+1.0 \mathrm{~V}$, respectively. Figure 11 shows the CVs of $2 \mathrm{mM} \mathrm{L}$-cysteine in $0.1 \mathrm{M} \mathrm{KCl}$ solution at the Li doped bismuth oxide nanorods modified GCE for the 1st and 20th time. The R.S.D. is $0.61 \%$ and $2.28 \%$ for cvp 1 and cvp2, respectively. The Li doped bismuth oxide nanorods modified GCE was stored in air at room temperature when the modified electrode was not in use. The current of electrochemical $\mathrm{CV}$ peaks maintains similar suggesting that the nanorods modified GCE is considerably stable.

\section{Conclusions}

In summary, Li doped bismuth oxide nanorods with monoclinic $\mathrm{Bi}_{2} \mathrm{O}_{4}$ and cubic $\mathrm{LiBi}_{12} \mathrm{O}_{18.50}$ phases have been synthesized by a hydrothermal process without any surfactants and templates. The nanorods have the length and diameter of 1-5 $\mu \mathrm{m}$ and 50-350 nm, respectively. The hydrothermal conditions can effectively affect the morphologies of the products. The electrochemical studies show that the Li doped bismuth oxide nanorods can be used as the GCE modified materials for the electrochemical determination of L-cysteine. There are two pairs of semi-reversible $\mathrm{CV}$ peaks located at $-0.41 \mathrm{~V},+0.25 \mathrm{~V}(\mathrm{cvp} 1$ and cvp1') and $-0.93 \mathrm{~V},-0.44 \mathrm{~V}$ (cvp2 and cvp2'), respectively. The intensities of the CV

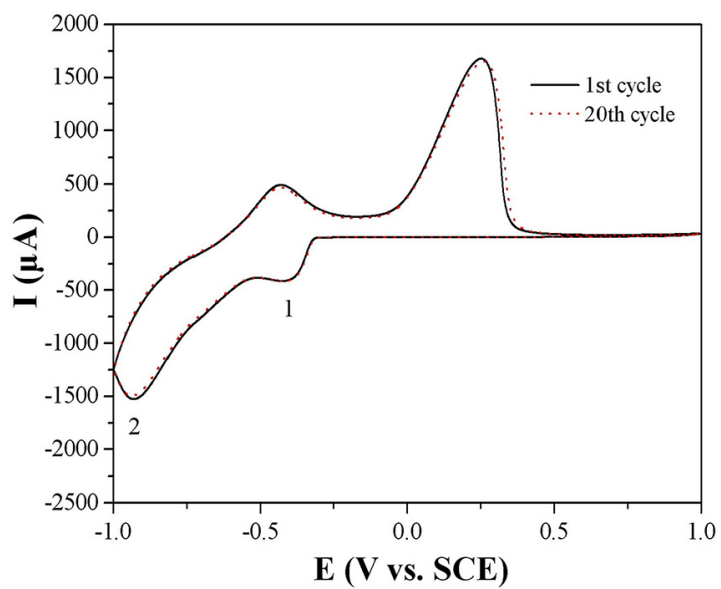

Figure 11. CVs of $2 \mathrm{mM} \mathrm{L-cysteine} \mathrm{at} \mathrm{the} \mathrm{Li} \mathrm{doped} \mathrm{bismuth} \mathrm{oxide}$ nanorods modified GCE in $0.1 \mathrm{M} \mathrm{KCl}$ solution for the 1st and 20th time, respectively. Scan rate, $50 \mathrm{mVs}^{-1}$.

peaks increase obviously and linearly with the increase of the scan rate and L-cysteine concentration. The detection limit is $0.36 \mu \mathrm{M}$ and $0.17 \mu \mathrm{M}$ for cvp1 and cvp2, respectively with good reproducibility and stability. The results suggest that the Li doped bismuth oxide nanorods belong to a promising electrode material for high performance electrochemical sensor for the detection of L-cysteine. 


\section{References}

1. Zhao M, Chen XL, Ma YJ, Jian JK, Dai L, Xu YP. $\mathrm{Bi}_{2} \mathrm{O}_{3}$ nanosquaresheets grown on Si substrate. Applied Physics $A$. 2004;78(3):291-293.

2. Kumari L, Lin JH, Ma YR. One-dimensional $\mathrm{Bi}_{2} \mathrm{O}_{3}$ nanohooks: synthesis, characterization and optical properties. Journal of Physics: Condensed Matter. 2007;19(40):406204.

3. Wang L, Wang X, Chen L, Chen C, Xiao X, Gao L, et al. Effects of ball-milling time and $\mathrm{Bi}_{2} \mathrm{O}_{3}$ addition on electrochemical performance of ball-milled $\mathrm{La}_{2} \mathrm{Mg}_{17}+200 \mathrm{wt}$. \% Ni composites. Journal of Alloys and Compounds. 2006;416(2-1):194-198.

4. Hyodo T, Kanazawa E, Takao Y, Shimizu Y, Egashira M. $\mathrm{H}_{2}$ sensing properties and mechanism of $\mathrm{Nb}_{2} \mathrm{O}_{5}-\mathrm{Bi}_{2} \mathrm{O}_{3}$ varistor-type gas sensors. Electrochemistry. 2000;68:24-31.

5. Pei LZ, Wei T, Lin N, Cai ZY, Fan CG, Yang Z. Synthesis of zinc bismuthate nanorods and electrochemical performance for sensitive determination of L-cysteine. Journal of The Electrochemical Society. 2016;163(2):H1-H8.

6. Pei LZ, Wei T, Lin N, Zhang H, Fan CG, Yang Z. Aluminium bismuthate nanorods and electrochemical performance for the detection of tartaric acid. Journal of Alloys and Compounds. 2016;679:39-46.

7. Su H, Cao S, Xia N, Huang X, Yan J, Liang Q, et al. Controllable growth of $\mathrm{Bi}_{2} \mathrm{O}_{3}$ with rod-like structures via the surfactants and its electrochemical properties. Journal of Applied Electrochemistry. 2014;44(6):735-740.

8. Zidan M, Tee TW, Abdullah AH, Zainal Z, Kheng GJ. Electrochemical oxidation of ascorbic acid mediated by $\mathrm{Bi}_{2} \mathrm{O}_{3}$ microparticles modified glassy carbon electrode. International Journal of Electrochemical Science. 2011;6(2):289-300.

9. Dutta DP, Roy M, Tyagi AK. Dual function of rare earth doped nano $\mathrm{Bi}_{2} \mathrm{O}_{3}$ : white light emission and photocatalytic properties. Dalton Transactions. 2012;41(34):10238-10248.

10. Ge H, Li N, Li D, Dai C, Wang D. Study on the effect of Li doping in spinel $\mathrm{Li}_{4+x} \mathrm{Ti}_{5-x} \mathrm{O}_{12}(0 \leq x \leq 0.2)$ materials for lithium-ion batteries. Electrochemical Communications. 2008;10(7):1031-1034.

11. Hayashi H, Tomizawa J, Hasegawa T, Akiyama Y. Low-temperature fabrication of $\mathrm{Pb}\left(\mathrm{Ni}_{1 / 3} \mathrm{Nb}_{2 / 3}\right) \mathrm{O}_{3}-\mathrm{Pb}\left(\mathrm{Zr}_{0.3} \mathrm{Ti}_{0.7}\right) \mathrm{O}_{3}$ ceramics with $\mathrm{LiBiO}_{2}$ as a sintering aid. Journal of the European Ceramic Society. 2004;24(6):1037-1039.

12. Wang X, Luo C, Li L, Duan H. Highly selective and sensitive electrochemical sensor for L-cysteine detection based on graphene oxide/multiwalled carbon nanotube/manganese dioxide/ gold nanoparticles composite. Journal of Electroanalytical Chemistry. 2015;757:100-106.

13. Zhang L, Ning L, Zhang Z, Li S, Yan H, Pang H, et al. Fabrication and electrochemical determination of L-cysteine of a composite film based on V-substituted polyoxometalates and $\mathrm{Au} @ 2 \mathrm{Ag}$ core-shell nanoparticles. Sensors and Actuators B: Chemical. 2015;221:28-36.

14 Wang YQ, Wang W, Wang S, Chu W, Wei T, Tao H, et al. Enhanced photoelectrochemical detection of L-cysteine based on the ultrathin polythiophene layer sensitized anatase $\mathrm{TiO}_{2}$ on F-doped tin oxide substrates. Sensors and Actuators B: Chemical. 2016;232:448-453.

15. Zaia DAM, Ribas KCL, Zaia CTBV. Spectrophotometric determination of cysteine and/or carbocysteine in a mixture of amino acids, shampoo, and pharmaceutical products using p-benzoquinone. Talanta. 1999;50(5):1003-1010.

16. Bydalek TJ, Poldoski JE. Spectrophotometric determination of cysteine. Analytical Chemistry. 1968;40(12):1878-1881.

17. Guan X, Hoffman B, Dwivedi C, Matthees DP. A simultaneous liquid chro-matography/mass spectrometric assay of glutathione, cysteine, homocysteine and their disulfides in biological samples. Journal of Pharmaceutical and Biomedical Analysis. 2003;31(2):251-261.

18. Yang S, Li G, Wang G, Deng D, Qu L. A novel electrochemical sensor based on $\mathrm{Fe}_{2} \mathrm{O}_{3}$ nanoparticles/N-doped graphene for electrocatalytic oxidation of L-cysteine. Journal of Solid State Electrochemistry. 2015;19(12):3613-3620.

19. Silva FAS, Silva MGA, Lima PR, Meneghetti MR, Kubota LT, Goulart MOF. A very low potential electrochemical detection of $L$-cysteine based on a glassy carbon electrode modified with multi-walled carbon nanotubes/gold nanorods. Biosensors and Bioelectronics. 2013;50:202-209.

20. Silva CCC, Breitkreitz MC, Santhiago M, Corrêa CC, Kubota LT. Construction of a new functional platform by grafting poly(4-vinylpyridine) in multi-walled carbon nanotubes for complexing copper ions aiming the amperometric detection of L-cysteine. Electrochimica Acta. 2012;71:150-158.

21. Lu H, Wang S, Zhao L, Dong B, Xu Z, Li J. Surfactant-assisted hydrothermal synthesis of $\mathrm{Bi}_{2} \mathrm{O}_{3}$ nano/microstructures with tunable size. RSC Advances. 2012;2(8):3374-3378.

22. Lin LW, Tang YH, Chen CS, Xu HF. Self-assembled single crystal germanium nanowires arrays under supercritical hydrothermal conditions. CrystEngComm. 2010;12(10):2975-2981.

23. Lin LW, Tang YH, Chen CS. Self-assembled silicon oxide nanojunctions. Nanotechnology. 2009;20(17):175601.

24. Lu H, Wang S, Dong B, Xu Z, Zhao L, Li J. One-step hydrothermal formation of $\mathrm{Bi}_{2} \mathrm{O}_{3}$ nanourchins with radially ultrathin nanotubes. Journal of the Physical Society of Japan. 2010;79(9):094802.

25. Lin L, Sun X, Jiang Y, He Y. Sol-hydrothermal synthesis and optical properties of $\mathrm{Eu}^{3+}, \mathrm{Tb}^{3+}$-codoped one-dimensional strontium germanate full color nano-phosphors. Nanoscale. 2013;5(24):12518-12531.

26. Wang F, Xing Y, Su Z, Song S. Single-crystalline $\mathrm{CuGeO}_{3}$ nanorods: Synthesis, characterization and properties. Materials Research Bulletin. 2013;48(7):2654-2660.

27. Li ZQ, Zhang L, Song Y, Chen XT, Musfeldt JL, Xue ZL. Size-controlled synthesis and magnetic properties of copper germanate nanorods. Observation of size-induced quenching of the spin-Peierls transition. CrystEngComm. 2014;16(5):850-857.

28. Pei L, Lin N, Wei T, Liu H, Yu H. Formation of copper vanadate nanobelts and their electrochemical behaviors for the determination of ascorbic acid. Journal of Materials Chemistry A. 2015;3(6):2690-2700. 
29. Pei LZ, Wang S, Jiang YX, Xie YK, Li Y, Guo YH. Single crystalline $\mathrm{Sr}$ germanate nanowires and their photocatalytic performance for the degradation of methyl blue. CrystEngComm. 2013;15(38):7815-7823.

30. Zhao K, Du G, Qin G, Liu Y, Zhao H. Facile synthesis of boscage-like $\mathrm{SnO}_{2}$ nanorods by hydrothermal method. Materials Letters. 2015;141:351-354.

31. Pei LZ, Cai ZY, Pei YQ, Xie YK, Fan CG, Fu DG. Electrochemical determination of L-cysteine using $\mathrm{CuGeO}_{3} /$ polyaniline nanowires modified electrode. Russian Journal of Electrochemistry. 2014;50(5):458-467.

32. Mimica D, Bedioui F, Zagal JH. Reversibility of the l-cysteine/lcystine redox process at physiological $\mathrm{pH}$ on graphite electrodes modified with coenzyme $\mathrm{B}_{12}$ and vitamin $\mathrm{B}_{12}$. Electrochimica Acta. 2002;48(4):323-329.

33. Xiao C, Chen J, Liu B, Chu X, Wu L, Yao S. Sensitive and selective electrochemical sensing of L-cysteine based on a caterpillar-like manganese dioxide-carbon nanocomposite. Physical Chemistry Chemical Physics. 2011;13(4):1568-1574.

34. Hager G, Brolo AG. Protonation and deprotonation of cysteine and cystine monolayers probed by impedance spectroscopy. Journal of Electroanalytical Chemistry. 2009;625(2):109-116.

35. Dong YP, Pei LZ, Chu XF, Zhang WB, Zhang QF. Electrochemical behavior of cysteine at a $\mathrm{CuGeO}_{3}$ nanowires modified glassy carbon electrode. Electrochimica Acta. 2010;55(18):5135-5141.

36. Dong Y, Zheng J. A nonenzymatic L-cysteine sensor based on $\mathrm{SnO}_{2}$-MWCNTs nanocomposites. Journal of Molecular Liquids. 2014;196:280-284.

37. Ziyatdinova G, Grigor'eva L, Morozov M, Gilmutdinov A, Budnikov H. Electrochemical oxidation of sulfur-containing amino acids on an electrode modified with multi-walled carbon nanotubes. Microchimica Acta. 2009;165(3):353-359.

38. Ahmad M, Pan C, Zhu J. Electrochemical determination of L-cysteine by an elbow shaped, Sb-doped $\mathrm{ZnO}$ nanowire-modified electrode. Journal of Materials Chemistry. 2010;20(34):7169-7174.

39. Tang X, Liu Y, Hou H, You T. Electrochemical determination of L-Tryptophan, L-Tyrosine and L-Cysteine using electrospun carbon nanofibers modified electrode. Talanta. 2010;80(5):2182-2186.

40. Lu CH, Yang HH, Zhu CL, Chen X, Chen GN. A graphene platform for sensing biomolecules. Angewandte Chemie. 2009;121(26):4879-4881.

41. Ao ZM, Peeters FM. Electric field activated hydrogen dissociative adsorption to nitrogen-doped graphene. Journal of Physical Chemistry C. 2010;114(34):14503-14509.
42. Dong YP, Huang L, Zhang J, Chu XF, Zhang QF. Electrooxidation of ascorbic acid at bismuth sulfide nanorod modified glassy carbon electrode. Electrochimica Acta. 2012;74:189-193.

43. Deng C, Chen J, Chen X, Wang M, Nie Z, Yao S. Electrochemical detection of 1-cysteine using a boron-doped carbon nanotubemodified electrode. Electrochimica Acta. 2009;54(12):3298-3302.

44. Spãtaru N, Sarada BV, Papa E, Tryk DA, Fujishima A. Voltammetric determination of L-cysteine at conductive diamond electrodes. Analytical Chemistry. 2001;73(3):514-519.

45. Dharmapandian P, Rajesh S, Rajasingh S, Rajendran A, Karunakaran C. Electrochemical cysteine biosensor based on the selective oxidase-peroxidase activities of copper, zinc superoxide dismutase. Sensors and Actuators B: Chemical. 2010;148(1):17-22.

46. Chen Z, Zheng H, Lu C, Zu Y. Oxidation of 1-cysteine at a fluorosurfactant-modified gold electrode: lower overpotential and higher selectivity. Langmuir. 2007;23(21):10816-10822.

47. Chen SM, Chen JY, Thangamuthu R. Electrochemical Preparation of brilliant-blue-modified poly(diallyldimethylammonium chloride) and nafion-coated glassy carbon electrodes and their electrocatalytic behavior towards oxygen and L-cysteine. Electroanalysis. 2008;20(14):1565-1573.

48. Salimi A, Hallaj R. Catalytic oxidation of thiols at preheated glassy carbon electrode modified with abrasive immobilization of multiwall carbon nanotubes: applications to amperometric detection of thiocytosine, L-cysteine and glutathione. Talanta. 2005;66(4):967-975.

49. Fei S, Chen J, Yao S, Deng G, He D, Kuang Y. Electrochemical behavior of L-cysteine and its detection at carbon nanotube electrode modified with platinum. Analytical Biochemistry. 2005;339(1):29-35.

50. Keyvanfard M, Salmani-mobarakeh R, Karimi-Maleh H, Alizad K. Application of 3,4-dihydroxycinnamic acid as a suitable mediator and multiwall carbon nanotubes as a sensor for the electrocatalytic determination of L-cysteine. Chinese Journal of Catalysis. 2014;35(7):1166-1172.

51. Ensafi AA, Dadkhah-Tehrani S, Karimi-Maleh H. A voltammetric sensor for the simultaneous determination of L-cysteine and tryptophan using a $p$-aminophenol-multiwall carbon nanotube paste electrode. Analytical Sciences. 2011;27(4):409-414. 